\title{
Mutations in human TBX3 alter limb, apocrine, and genital development in ulnar-mammary syndrome
}

Michael Bamshad, Robert C. Lin, David J. Law, W. Scott Watkins, Patrycja A. Krakowiak, Mary E. Moore, Piergiorgio Franceschini, Roberto Lala, Lewis B. Holmes, Tom C. Gebuhr, Benoit Bruneau, Albert Schinzel, John G. Seidman, Christine E. Seidman \& Lynn B. Jorde

Nature Genet. 16, 311-315 (1997).

In sequencing additional TBX3 cDNA clones, Dr. Chris Campbell brought to our attention a single base insertion at nt 1107 which causes a frameshift in the TBX3 sequence (GenBank accession number AF002228). Sequencing of PCR-derived genomic templates of $T B X 3$ confirms this finding. A corrected TBX3 sequence from the start of exon 6 to the end of the published sequence is shown below. The authors regret this error.

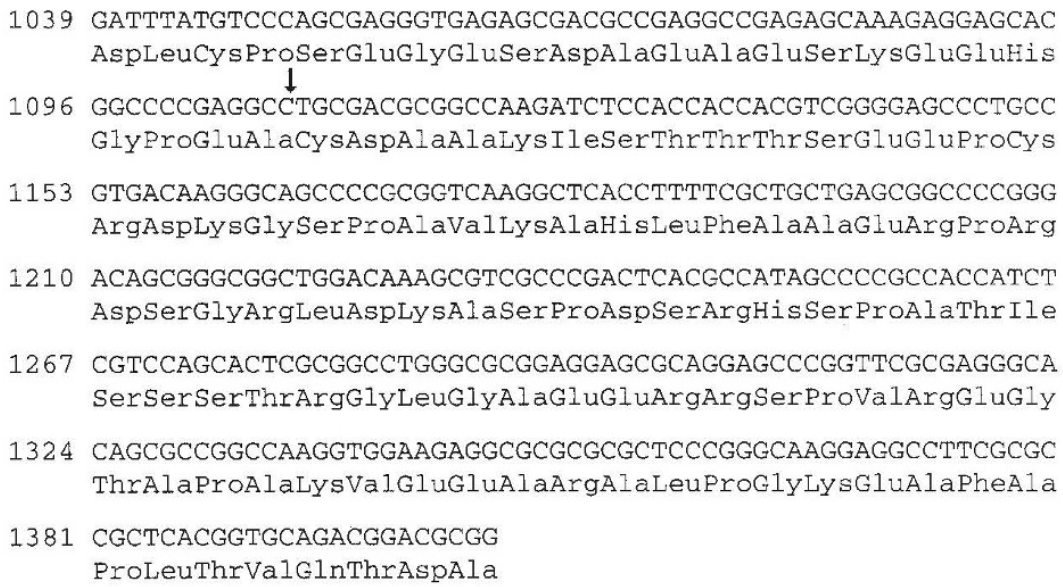

\section{Growth retardation and tumour inhibition by $B R C A 1$}

Jeffrey T. Holt, Marilyn E. Thompson, Csilla Szabo, Cheryl Robinson-Benion, Carlos L. Arteaga, Mary-Claire King \& Roy A. Jensen

Nature Genet. 12, 298-302 (1996).

The sequence of the BRCA1 cDNA presumed to be wild-type in these studies actually was that of a splice variant with an altered exon 5 containing nucleotides 22201-22256 (compared with wild-type exon 5 at nucleotides 22201-22278 of GenBank L78833 genomic sequence). This altered splicing results in a protein which inititates at amino acid 72 of wild-type BRCA1. The altered sequence is published ${ }^{1}$ and the complete splice variant sequence available in GenBank (AF 005068). This error does not affect our main conclusions, as we have subsequently reported that both the prior splice variant and the new full-length $B R C A 1 \mathrm{cDNA}$ function as growth inhibitors and tumour suppressors ${ }^{1}$.

$$
\begin{array}{rcc}
\text { TGT CCT TT ATG } & \text { (taagaatgatataaccaaaagg) } & \text { AGC CTA CAA } \\
\text { splice donor } & \text { (22 bp spliced from exon 5) } & \text { splice acceptor }
\end{array}
$$

1. Tait, D.L. et al. A Phase I trial of retroviral BRCA1sv gene therapy in ovarian cancer. Clin. Cancer Res. 3, 1959-1978 (1997).

\section{erratum}

\section{Distribution of olfactory receptor genes in the human genome}

Sylvie Rouquier, Sylvie Taviaux, Barbara J. Trask, Véronique Brand-Arpon, Ger van den Engh, Jacques Demaille \& Dominique Giorgi Nature Genet. 18, 243-250 (1998).

Part of the discussion was inadvertantly sent to press without the incorporation of the authors' corrections. The correct version is shown below. We regret this error.

Out of 53 sites detected more than once, 28 were labelled with an efficiency $>5 \%$, a level considered significant considering the small size of the probes and complex nature of the probe-pool. Several arguments lead to the conclusion that OR genes are very likely to reside at many of the sites detected less efficiently. The specificity and sensitivity of our FISH approach for locating OR sequences are demonstrated by the observation that all previously reported locations of OR genes were detected. 